\title{
Investigación cualitativa sobre las Croatas en Chile y su relación actual con sus orígenes
}

\section{Qualitative research on Croats in Chile and their current relation with their origins}

\author{
Ana Dujlovic \\ Departamento de Antropología, Universidad de Chile \\ ORCID 0000-0003-2509-4472 \\ adujlovic@gmail.com
}

\section{Resumen}

Hoy en día muchos habitantes en Chile son descendientes de emigrantes croatas que de cierta manera conservan sus orígenes. La investigación realizada examinó las formas en que los participantes mantienen su relación con Croacia y su origen, cuáles son sus sentimientos, pensamientos y actividades relacionadas con Croacia. En la investigación los participantes con sus respuestas, mostraron que el vínculo entre Croacia y Chile todavía sigue fuerte, independientemente del tiempo pasado y la distancia que los separa.

Palabras claves: Croacia, Chile, origenes, comunidad, identidad

\section{Abstract}

Today many Chilean habitants are descendants of Croatian emigrants that in a certain way conserve their Croatian origin. The conducted research investigates about the relation that participants have with Croatia and their origin, which are their feelings, thoughts and activities related to Croatia. The research shows that the relation between Croatia and Chile maintains strong regardless of the time and the distance that separates them.

Key words: Croatia, Chile, origin, community, identity

\section{Introducción}

Para los Croatas, una de las mayores migraciones de la historia fue la emigración de la población a Chile en donde forman una de las comunidades europeas más grandes de Sudamérica (Lasić, 2009, pg 163). Las razones de la migración fueron principalmente de naturaleza económica, relacionadas con las problemas agriculturales y crisis de las empresas marítimas que ocurrieron en el sur de Croacia durante los finales del siglo 19 y principio del siglo 20 por lo que la mayoría de la población emigró desde el área de Dalmacia (Adamović, Mežnarić, 2007, pg 94). El Ministerio de Asuntos Exteriores de Chile estima que aproximadamente 200000 personas de origen Croata viven en Chile y esta es la tercera, cuarta o en algunos casos, la quinta generación de descendientes de inmigrantes croatas. Con el fin de preservar su identidad nacional, muchos Croatas que llegaron a Chile han establecido comunidades en las que se, por ejemplo, practican bailes y canciones folclóricas, se preparan comidas tradicionales, se realizan talleres de antiguas costumbres o simplemente se reúnen las personas que comparten el mismo origen. Hoy en día, 
hay muchos descendientes de inmigrantes Croatas que viven en Chile que aún intentan preservar sus raíces de manera que algunos son también los miembros de estas comunidades mencionadas, visitan Croacia, mantienen el contacto con sus conocidos en Croacia o de alguna otra forma expresan su asociación. El propósito de esta investigación es investigar el estado actual de los descendientes Croatas en Chile, al igual que su relación con sus orígenes ahora, décadas después de la época de las grandes migraciones. Las previas investigaciones se ha realizado principalmente sobre la base de fuentes históricas sobre la migración Croata, pero esta investigación se realizó con el objetivo de conocer actual población Chilena de origen Croata y su relación con su origen mediante un cuestionario. El cuestionario en línea recopiló la información sobre lo que actualmente piensan, conocen y sienten los participantes de origen Croata sobre Croacia, en qué actividades están involucrados en la vida cotidiana y cuál relación tienen con sus raíces Croatas.

\section{Metodología}

Esta investigación ha sido realizada utilizando el cuestionario en línea compuesto de doce preguntas de forma cerrada para recolectar datos cuantitativos y cinco preguntas abiertas para la recolección de los datos cualitativos. La encuesta se distribuyó a través de redes sociales y correo electrónico contactando a las comunidades de Croatas en Chile pidiéndoles mandar la encuesta a sus miembros y otros contactos de orígenes Croatas. Los datos se recopilaron durante abril y mayo de 2019 y después se analizaron con el software para análisis de datos cualitativos llamado Atlas.ti.

Las preguntas cuantitativas del cuestionario son las siguientes: ¿Cuál es su género?, ¿Cuál es su edad?, ¿En que parte de Chile vive?, ¿Forma parte de alguna organización Croata en Chile?, ¿Si su respuesta anterior era si, cual organización es?, ¿Cuando llegaron sus primeros antepasados de Croacia?, ¿Tiene ciudadanía Croata?, Evalúa su conocimiento de idioma Croata en la escala de 1 (No hablo Croata) a 5 (Hablo fluido), Evalúa su sentimiento de pertenencia a Croacia en la escala de 1 (No siento pertenencia) a 5 (Siento pertenencia totalmente), ¿Cuántas veces has visitado a Croacia?, ¿Tiene algunos conocidos en Croacia? y ¿De que parte de Croacia vienen sus antecesores?

Para los datos cualitativos se formaron las siguientes preguntas: ¿Qué significa Croacia para ti?, Describe sus experiencias relacionadas con Croacia en cuales participa., Describe cómo ves a la comunidad Croata en Chile., ¿Como es Chile en comparación con Croacia? y ¿Qué siente sobre Croacia y al ver su bandera?

Finalmente a la encuesta respondieron 46 participantes, todos incluidos a la análisis hecha después de la recolección de datos. La muestra está compuesta de un número similar de mujeres $(N=24)$ y hombres $(N=22)$ en el rango de 21 a 81 años. Los participantes son de varias partes de Chile, de norte a sur del país con el mayor número de participantes de la capital, Santiago ( $N=23)$. En la muestra, el número de encuestados que participan en alguna de las organizaciones de la comunidad croata en Chile $(N=21)$ es similar al número de los que no son miembros de ninguna organización $(N=25)$. Participantes mencionan algunas de las numerosas asociaciones de 
Croatas en Chile como por ejemplo Circulo de profesionales y empresarios de ascendencia Croata (CPEAC), Corporación cultural Chileno Croata Domovina, Estadio Croata, Club Croata de Punta Arenas, Colonia Croata Arica y Sociedad Croata Antofagasta.

El mayor porcentaje, $71,7 \%$ de participantes $(N=33)$ respondió que sus primeros antepasados Croatas llegaron en la primera mitad del siglo XX. El 19,6\% $(N=9)$ de los participantes respondió que sus antepasados llegaron antes del siglo XX y 8,7\% $(N=4)$ indica que sus ancestros provienen de la segunda mitad del siglo 20 . El lugar de llegada de los antepasados Croatas de $93 \%$ de los participantes $(N=43)$ fue la región Splitsko-dalmatinska. Otras regiones mencionadas con un participante de cada una son Viroviticko- podravska, Zadarska y Sibensko-kninska. La ciudadanía Croata tiene 11 participantes mientras 34 no la poseen.

El mayor número de participantes en el conocimiento del idioma Croata se califica con 1, el grado más bajo $(N=24)$ y la calificación promedia de todos los encuestados es 1,652 . Sin embargo, el mayor número de encuestados respondió sobre su sentimiento de pertenencia a Croacia con la puntuación más alta $5(N=20)$, mientras que la calificación promedia del sentimiento de pertenencia fue 3,898 . A la pregunta sobre la cantidad de veces que habían visitado Croacia, el $43 \%(N=24)$ de los encuestados respondieron que nunca habían estado en Croacia, el $26 \%$ $(N=12)$ visitaron una vez y el otro $21 \%(N=10)$ le habían visitado varias veces. El $48 \%(N=22)$ de los encuestados afirma que en Croacia tienen familiares, los amigos en Croacia tiene el 26\% $(N=12)$ y el $24 \%(N=11)$ no tienen ningún conocido.

\section{Análisis}

Se formularon seis preguntas cualitativas para recopilar información más detallada sobre cómo se relacionan los participantes con su origen y cuál es su significado emocional, cómo se asocian con las costumbres Croatas y con otros miembros de la comunidad Croata en su vida cotidiana, cuál es su opinión en general sobre Croacia y cómo la comparan con Chile.

A la pregunta '¿Qué significa Croacia para ti?' los participantes respondieron con diversas descripciones cuales son las siguientes: amor, antepasados, belleza, calidad, crianza, cultura, país emprendedora, familia, gente buena y trabajadora, identidad, gran importancia, orgullo, origen, segunda patria y tranquilidad. De las diversas respuestas se puede concluir que las raíces croatas tienen una gran importancia para los participantes y en general, tienen opinión positiva sobre Croacia.

Los participantes asocian Croacia principalmente con sus orígenes y familia que demuestran las afirmaciones como "es la cuna de mis antepasados", "unión permanente con mi padre", "la tierra de mis abuelos" y "la cuna de una forma de vida". En general, dicen que les gusta mantener sus raíces por el amor por sus antepasados y mencionan una serie de asociaciones positivas como el amor y el orgullo hacia Croacia, la sensación de que Croacia es parte de su identidad y que también la consideran como su patria. 
La segunda pregunta 'Describe sus experiencias relacionadas con Croacia en cuales participa.' recopiló los datos sobre las actividades y experiencias de los encuestados en su vida cotidiana que de alguna manera son relacionadas con sus orígenes Croatas. Las experiencias mencionadas se relacionan con siguientes expresiones: gente amable, baile folclórico (7), música folclórica, buenas experiencias, ciudadanía, comida típica, conservación cultural, curso de idioma, participación en Circulo de profesionales y empresarios Croatas, participación en corporación Domovina y Estadio Croata, familia, redes sociales, fútbol, ganas de visitar y conocer más, talleres de gastronomía, noticias y ganas de volver a vivir.

Algunas de las experiencias en cuales los participantes mantienen su identidad Croata son las experiencias en organizaciones de los Croatas en Chile, donde por ejemplo bailan bailes folclóricos, cantan canciones tradicionales y se reúnen, socializan y transmiten la cultura Croata. Algunas de las descripciones de las experiencias en las respuestas son: 'he participado toda mi vida en en la colonia y los bailes y comida me encantan', 'participo en Domovina, corporación chileno-croata cuya misión es conservar las raíces croatas como homenaje a los Croatas que vinieron a Chile' y 'participo en talleres de lengua, de gastronomía y ocasionalmente otros de cultura Croata'. La otra parte de los participantes, las experiencias relaciona con su viaje a Croacia y sus conocidos como en las siguientes citas: 'he vuelto a ir varias veces y he apreciado una evolución importante, especialmente en los últimos años. Me encanta ir a Croacia', 'conocí a mi familia croata' y 'Me comunico con paisanos con frecuencia'.

Los participantes también describen la comunidad croata en Chile formada por todos los Croatas de origen Chileno que mantienen sus orígenes de cierta manera. Las palabras con las que describen a dicha comunidad en algunos casos con opuestos. Las descripciones de la comunidad de los encuestados en una pieza son bastante activas y están unidas para preservar la economía croata y reunir a los miembros que desean preservar sus orígenes. Una parte de los participantes relaciona a la comunidad con palabras positivas como los siguientes: abierta, activa, alegre, amable, aporte, cálida, compromiso, consciente, creciendo, emprendedora, esfuerzo,grande, hermosa, interés, orgullo, potente, promoción cultura, trabajadora y unida. Estos participantes la describen como una gran comunidad, amigable, unida, esforzada y una comunidad que está creciendo y avanzando como en las siguientes afirmaciones: 'Uniéndose cada día más', 'Como bastante grande, variada y a los que he conocido son muy integradores y amables' y 'Veo que está mejorando la unión y participación'.

Por otro lado, una parte de los encuestados tiene una visión diferente de la comunidad y la describen con siguientes palabras: disgregada, decaída, escondida, fría, poco conocimiento, y sin saber idioma. Estos participantes piensan que la comunidad de hoy está menos unida que antes, que hay menos miembros y muchas asociaciones más pequeñas que no se comunican entre sí. Las citas que demuestran estas opiniones son: 'un poco decaída ya que ya van quedando pocos inmigrantes nacidos en Croacia' y 'no la veo muy unida' y 'la comunidad croata en Chile está muy disgregada en Santiago'.

Para examinar cómo los participantes ven Chile en comparación con Croacia se formó la pregunta ¿Cómo es Chile en comparación con Croacia?. Las comparaciones encontradas se 
dividen en las respuestas que expresan opinión positiva hacia Croacia, las opiniones más positivas sobre Chile y a las que favorecen a ambos países. Los primeros describen Croacia como país muy seguro, amigable, desarrollado como las siguientes citas: 'Chile es mucho más grande en área, hay mucha gente y es inseguro, al menos yo, aquí, siempre pienso que me pueden asaltar; en Croacia no tuve nunca esa sensación', 'Es muy diferente, no tiene comparación, en croacia todo es mejor, la gente es más honesta, hay mejores sistemas de vida en general.' y 'En todo sentido me gusta más Croacia' y 'Chile es un país más segmentado socialmente, y en general más hostil'. Por otro lado, algunos participantes describen Chile como un pais con mas gente amigable, más diverso y desarrollado: 'Un país mucho más diverso en clima, geografía y población.', 'La gente de chile es más amigable y cálida', 'Chile es más desarrollado en el sentido económico y de PIB.' El resto de los participantes describen ambas países como hermosas, pequeñas y similares con las citas como: 'Ambos son países pequeños, con poca gente y muy hermosos', 'Encuentro que se parecen en algo, países pequeños con espíritu emprendedor’ y ‘Es muy similar en cuanto a economía y paisajes'.

Con el objetivo de recopilar los datos sobre los sentimientos de los participantes hacia Croacia en el cuestionario se preguntó ¿Qué siente sobre Croacia y al ver su bandera? y se recolectaron las siguientes expresiones: alegria, amor, belleza, cariño, emoción, esfuerzo, esperanza, familia, identidad, impotente, interés, maravilla, nostalgia, orgullo, origen, pertenencia, recuerdos y respeto. El mayor número de encuestados vinculó la bandera con el sentimiento de orgullo, como se puede ver en las siguientes citas: 'Orgullo de mis raíces' 'Un sentimiento de amor y orgullo muy profundos' y 'Me emociona y siento orgullo al verla'.

\section{Conclusión}

De la investigación realizada se puede concluir que el origen croata es de gran importancia para los descendientes Croatas en Chile, independientemente del hecho de que también hay participantes que pertenecen a la cuarta generación desde a primera llegada de sus antepasados a Chile, aunque la mayoría no conoce el idioma croata o aún no ha visitado a Croacia. La mayoría de ellos mantienen su relación con su origen, participando en numerosas organizaciones que reúnen Croatas en Chile y también Croacia para ellos tiene un significado importante en la vida cotidiana, forma parte de su identidad y provoca fuertes sentimientos positivos como el amor y el orgullo. De lo anterior, se puede concluir que ni el paso del tiempo, ni la gran distancia entre la ubicación de Croacia y la de Chile, no separaron significativamente la conexión de estos dos países causada por los movimientos migratorios en el pasado.

Nota: Este trabajo de investigación se realizó dentro de la asignatura software para análisis de datos cualitativos en el primer semestre de 2019. 


\section{Bibliografía}

Adamović, M., \& Mežnarić, S. (2007). Croatian Immigrants in Chile. AEMI journal, 16(5), 93106.

Lasić, J. (2009). Jezični identitet hrvatske iseljeničke zajednice u Čileu. Croatian Studies Review-Časopis hrvatskih studija, 13(6), 163-171.

Središnji državni portal. Obtenido 21/6/2019 de https://hrvatiizvanrh.gov.hr/hrvati-izvan$\underline{\text { rh/hrvatsko-iseljenistvo/hrvatsko-iseljenistvo-u-cileu/756 }}$ 